\title{
Effects of the Timolol-Dorzolamide Fixed Combination and Latanoprost on Circadian Diastolic Ocular Perfusion Pressure in Glaucoma
}

\author{
Luciano Quaranta, ${ }^{1}$ Stefano Miglior, ${ }^{2}$ Irene Floriani,${ }^{3}$ Teodoro Pizzolante, ${ }^{1}$ and \\ Anastasios G. P. Konstas ${ }^{4}$
}

Purpose. To evaluate the effect of the timolol-dorzolamide fixed combination (TDFC) and latanoprost $0.005 \%$ on 24 -hour intraocular pressure (IOP), systolic (SBP) and diastolic (DBP) blood pressure, and diastolic ocular perfusion pressure (DOPP) in patients with primary open-angle glaucoma (POAG).

Methods. This was an institutional, randomized clinical trial. After a 24-hour assessment without treatment, 27 previously untreated patients with POAG were randomized to 6 weeks' treatment with twice-daily TDFC ( $8 \mathrm{AM}$ and $8 \mathrm{PM}$ ) followed by once-daily latanoprost $0.005 \%$ (8 PM), or vice versa. One eye was analyzed per patient. The mean values of IOP, DBP, SBP, and DOPP (difference between DBP and IOP) were recorded at each time point, and the 24-hour data are the mean values of each patient's measurements over the 24-hour period. The differences between the values of the first treatment period and the baseline and the second treatment period and washout were calculated and analyzed by means of an analysis of variance model that tested the effects of sequence and treatment.

RESULTS. Both treatments significantly reduced 24-hour IOP $(P<0.0001)$, but TDFC led to lower 24-hour pressure (mean \pm SD: $15.4 \pm 1.9$ vs. $16.7 \pm 1.7 \mathrm{~mm} \mathrm{Hg} ; P=0.004$ ). Latanoprost did not lead to any significant reduction in mean 24-hour SBP and DBP (SBP: $P=0.952$; DBP: $P=0.831$ ), but TDFC did (SBP and DBP: $P<0.0001$ ). Both treatments significantly increased 24-hour DOPP $(P<0.0001)$, with no difference between the two medications $(P=0.09)$.

Conclusions. In previously untreated patients with POAG, TDFC, and latanoprost equally enhanced 24-hour DOPP: the former by counteracting the decrease in DBP with a substantial reduction in IOP and the latter by not affecting DBP and significantly reducing IOP. (isrctn.org number, ISRCTN67123277.) (Invest Ophthalmol Vis Sci. 2008;49:4226-4231) DOI:10.1167/iovs.08-1744

$\mathbf{R}$ educing intraocular pressure (IOP) is currently the gold standard of primary open-angle glaucoma (POAG) therapy,${ }^{1-4}$ even though high IOP is not the only risk factor involved in the pathogenesis of the disease. ${ }^{5}$

Several population-based epidemiologic studies have shown that low diastolic blood pressure (DBP) and a diastolic ocular

From the ${ }^{1}$ Clinica Oculistica, Università degli Studi Brescia, Brescia, Italy; the ${ }^{2}$ Clinica Oculistica, Policlinico di Monza, Universitá Milano Bicocca, Monza, Italy; the ${ }^{3}$ Istituto di Ricerche Farmacologiche "Mario Negri," Milan, Italy; and the ${ }^{4}$ Glaucoma Unit, 1st Department of Ophthalmology, Aristotle University of Thessaloniki, Thessaloniki, Greece.

Submitted for publication January 16, 2008; revised April 7 and May 9, 2008; accepted August 8, 2008.

Disclosure: L. Quaranta, None; S. Miglior, None; I. Floriani, None; T. Pizzolante, None; A.G.P. Konstas, None.

The publication costs of this article were defrayed in part by page charge payment. This article must therefore be marked "advertisement" in accordance with 18 U.S.C. $\$ 1734$ solely to indicate this fact.

Corresponding author: Luciano Quaranta, Clinica Oculistica, Piazzale Spedali Civili 1, 25123 Brescia, Italy; quaranta@med.unibs.it. perfusion pressure (DOPP) of $<50$ to $55 \mathrm{~mm} \mathrm{Hg}$ are closely associated with the prevalence ${ }^{6-9}$ and incidence ${ }^{10}$ of POAG, and it has recently been reported that low blood pressure (BP) is also a risk factor for progression of glaucoma. ${ }^{11}$ It therefore seems reasonable that medical treatment for POAG should lower IOP without decreasing DOPP, which may be induced by an insufficient reduction in IOP or a decrease in BP.

However, there is little available information concerning the potential effects of current medical therapy on DOPP, particularly its effect on 24-hour IOP and BP patterns. The only study investigating the 24-hour curve of IOP and DOPP in patients with glaucoma ${ }^{12}$ found that latanoprost induced a fairly uniform reduction in IOP and a concomitant increase in DOPP over 24 hours, whereas dorzolamide reduced IOP to a lesser extent, although the increase in DOPP was not significantly different from that induced by latanoprost. Timolol and brimonidine significantly reduced 24-hour IOP, but did not significantly increase 24-hour DOPP, which was explained as being mainly a secondary effect of both on BP

In the light of these results, it was interesting to assess the efficacy of the timolol-dorzolamide fixed combination (TDFC), as the concomitant presence of both drugs should not only significantly reduce IOP, but should also affect DOPP. TDFC has already been extensively investigated, but most studies have evaluated its effect on office IOP, ${ }^{13-16}$ and only two have evaluated its effect on 24-hour IOP in patients with POAG, finding that it was substantially equivalent to that of latanoprost. ${ }^{17,18}$

The purpose of this study was to compare the effects of TDFC and latanoprost (which has been shown to increase $\mathrm{DOPP}^{12}$ ) on 24-hour IOP, BP, and DOPP profiles in a selected population of newly diagnosed and previously untreated patients with POAG, who were unaffected by or being treated for systemic hypertension as hypertension and its treatment may unpredictably affect 24 -hour $\mathrm{BP}^{19}$ and interfere with the reduction in IOP induced by timolol. ${ }^{20}$

\section{MeTHODS}

The study involved 27 consecutive, newly diagnosed, previously untreated patients with POAG $>45$ years of age with no history of eye surgery or laser treatment, who attended the Glaucoma Service of the University of Brescia, Italy. The inclusion criteria were open angle by gonioscopy (grade III-IV according to Shaffer's grading system); an untreated diurnal IOP of 22 to $32 \mathrm{~mm} \mathrm{Hg}$ (mean of the two highest values recorded on a daytime IOP curve of measurements made every 2 hours between $8 \mathrm{AM}$ and $6 \mathrm{PM}$, using a calibrated Goldmann applanation tonometer), as assessed by means of two IOP trials repeated on two different days ( 1 week apart); an optic disc with diffused/localized thinning of the neuroretinal rim and/or diffused/localized increase in cupping; a visual acuity of 20/40 or better; a mean deviation of $<-6$ dB (Humphrey 24-2 program, Humphrey Visual Field Analyzer Model 745; Carl Zeiss S.p.A, Arese, Italy), confirmed by two consecutive measurements; no history of allergy to the ingredients of any of the study drugs; no history of cardiovascular disease (e.g., arterial hyper- 
tension, heart disease, and arrhythmia), and no concomitant systemic treatment that may modify BP ( $\beta$-blockers, angiotensin-converting enzyme inhibitors, calcium channel blockers, and diuretics). Women were enrolled only if they were postmenopausal or were using contraceptives.

The study protocol adhered to the tenets of the Declaration of Helsinki and was approved by the local institutional review board (IRB; Clinica Oculistica, University of Brescia). Informed consent was obtained from all participants.

The enrolled patients underwent 24-hour IOP and ambulatory BP monitoring during a 3-day hospitalization period. IOP was measured every 2 hours by using a calibrated Goldmann applanation tonometer (GAT; Haag-Streit, Bern, Switzerland) to measure sitting IOP at the slit lamp between $8 \mathrm{AM}$ and $10 \mathrm{PM}$ and a calibrated handheld electronic tonometer (TonoPen XL; BioRad, Glendale, CA) to measure supine IOP between 12 and $6 \mathrm{AM}$ with the patient in bed. The mean of three consecutive readings was calculated for each time point. IOP measurements were made by three well-trained observers who were unaware of the treatment assignments. Their agreement was tested in a pilot sample of 15 patients, which led to an intraclass correlation coefficient of 0.97 for handheld tonometry and 0.99 for Goldmann tonometry.

Ambulatory BP was recorded by means of an automated portable TM-2430 (A\&D Co., Saitama, Japan), which indirectly measured BP by means of the oscillometric measurement of the vibratory signals associated with blood flow in the brachial artery. The device satisfies the systolic and diastolic BP accuracy levels recommended by the British Hypertension Society and the Association for Advancement of Medical Instrumentation. ${ }^{21} \mathrm{~A}$ cuff of appropriate size was placed on the subject's nondominant arm, and BP was measured automatically every 15 minutes between $8 \mathrm{AM}$ and $10 \mathrm{PM}$ and every 30 minutes between 10 $\mathrm{PM}$ and $8 \mathrm{AM}$. If a reading was not performed properly, the device was programmed to repeat it. The $\mathrm{BP}$ values recorded throughout the 24-hour period were subsequently recovered from the recording chip and stored on a personal computer.

Hospital 24-hour BP and IOP were monitored on separate days to prevent the IOP measurement process from affecting the BP readings.

The study had a randomized, blinded observer, two-treatment, and two-period crossover design. After the baseline IOP and BP measurements had been recorded, the patients were randomly assigned to one of the two treatment sequences (TDFC-latanoprost; latanoprostTDFC), and prescribed 1 drop of TDFC twice daily (at 8 AM and $8 \mathrm{PM}$ ) or 1 drop of latanoprost once daily (at 10 PM). The 6-week treatment periods were separated by a 4 -week washout period. The subsequent 24-hour IOP and BP measurements were made at baseline, at the end of the first treatment period, after the 4-week washout period (second baseline), and at the end of the second treatment period.

At baseline, the patients were hospitalized in the afternoon of day 1. The first IOP measurement was made at $8 \mathrm{AM}$ on day 2 and then every 2 hours as described earlier. The last IOP measurement was made at $6 \mathrm{AM}$ on day 3. After this last IOP measurement, the patients were fitted with the dynamic BP measuring device, which was kept in place for 24 hours (until 7 AM on day 4).

At the end of the first treatment period, the patients were hospitalized in the afternoon of day 1, and TDFC or latanoprost were administered at $8 \mathrm{PM}$ by the dosing coordinator of the study. The first IOP measurement was made at $8 \mathrm{AM}$ on day 2 (just before the morning instillation of TDFC at $8 \mathrm{AM}$ ) and then every 2 hours as described above; the last IOP measurement was made at $6 \mathrm{AM}$ on day 3. After this last IOP measurement, the patients were fitted with the dynamic BP measuring device, which was kept in place for 24 hours (until $7 \mathrm{AM}$ on day 4); during BP monitoring, the study drugs were administered as described earlier.

The same procedures were then repeated at the end of the washout period and at the end of the second treatment period.

The patients underwent a complete ocular and systemic examination at baseline and at the end of each phase of the trial, and all ocular or systemic adverse events were recorded.
One eye was analyzed per patient. If both eyes were eligible, one was randomly selected for statistical analysis. The mean \pm SD of IOP, DBP, SBP, and DOPP (calculated as the difference between DBP and IOP) were recorded at each time point, and the 24-hour data are the mean of each patient's measurements over the 24-hour period. The differences between the values in each treatment period and the baseline or washout values were calculated and analyzed by means of an analysis of variance model that tested the effects of sequence and treatment, and the same analysis was also applied separately to the day (from $8 \mathrm{AM}$ to $10 \mathrm{PM}$ ) and night (from 12 to $6 \mathrm{AM}$ ) glaucoma.

The sample size provided a $90 \%$ power to detect a standardized effect size in 24-hour IOP and 24-hour DOPP of at least 0.65 at a significance level of 0.05 for a two-sided test. According to Cohen, ${ }^{22}$ such an effect size corresponds to a medium-high effect.

The analyses were made using SAS software (Statistical Analysis System, ver. 9.0; SAS Institute Inc., Cary, NC). Data are expressed as the mean (SD).

\section{Results}

All 27 enrolled patients completed all the study phases, during which no serious adverse events were observed. Table 1 shows the descriptive statistics of the patients. To keep a logical sequence, IOP- and BP-related results are reported first, as they are the basis for DOPP calculation. There were no significant differences in IOP or BP between the baseline values and those obtained after the washout period, thus suggesting the absence of any carryover effect.

\section{Intraocular Pressure}

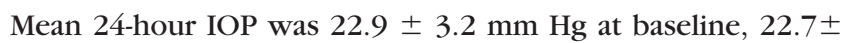
$2.9 \mathrm{~mm} \mathrm{Hg}$ at the end of the washout period, $15.4 \pm 1.9 \mathrm{~mm}$ $\mathrm{Hg}$ after TDFC, and $16.7 \pm 1.7 \mathrm{~mm} \mathrm{Hg}$ after latanoprost. Both therapies significantly reduced IOP in comparison with baseline $(P<0.0001)$. The observed reduction was $-7.4 \mathrm{~mm} \mathrm{Hg}$ (95\% CI: -7.8 to -6.9$)$ with TDFC, and $-6.1 \mathrm{~mm} \mathrm{Hg}$ (95\% CI: -6.5 to -5.6$)$ with latanoprost, with a significant difference in treatment effect in favor of TDFC $(-1.3 \mathrm{~mm} \mathrm{Hg}$ [95\% CI: -1.5 to -1.1 ] $P<0.0001$ ) (Table 2 ). Analysis of variance of the differences in comparison with baseline showed no treatment sequence effect $(P=0.331)$.

The reduction from baseline during the day was greater with TDFC than with latanoprost $(-7.7 \mathrm{~mm} \mathrm{Hg}$ [95\% CI: -8.2 to -7.1 ] vs. $-6.5 \mathrm{~mm} \mathrm{Hg}$ [95\% CI: -7.0 to -5.9$])$; the difference between treatments $(-1.2 \mathrm{~mm} \mathrm{Hg}$ [95\% CI: -1.7 to $-0.8])$ was statistically significant $(P<0.0001)$. The reduction from baseline during the night was also greater with TDFC ( $-6.7 \mathrm{~mm} \mathrm{Hg}$ [95\% CI: -7.3 to -6.0 ] vs. $-5.3 \mathrm{~mm} \mathrm{Hg}$ [95\% CI: -5.8 to -4.8$]$ ), and the between-treatment difference was also statistically significant $(-1.4 \mathrm{~mm} \mathrm{Hg}[95 \% \mathrm{CI}:-2.1$ to -1.6$]$; $P=0.001)$

\section{Systolic Blood Pressure}

Mean 24-hour SBP was 125.0 (4.5) $\mathrm{mm} \mathrm{Hg}$ at baseline, 125.0 (4.4) $\mathrm{mm} \mathrm{Hg}$ at the end of the washout period, 122.0 (4.2) $\mathrm{mm}$ $\mathrm{Hg}$ after TDFC, and 125.0 (4.4) $\mathrm{mm} \mathrm{Hg}$ after latanoprost.

TABLE 1. Patients' Characteristics

\begin{tabular}{lc}
\hline Patients $(n)$ & 27 \\
Age, $\mathrm{y}^{*}$ & $61(4.5)$ \\
Male, $n(\%)$ & $11(40.7)$ \\
Baseline IOP (SD), mm Hg* & $25.4(2.6)$ \\
Baseline SBP (SD), mm Hg* & $124.3(4.6)$ \\
Baseline DBP (SD), mm Hg* & $74.2(5.4)$ \\
\hline
\end{tabular}

\footnotetext{
${ }^{*}$ Mean (SD).
} 
TABLE 2. Intraocular Pressure by Study Phases

\begin{tabular}{lllll}
\hline \multicolumn{1}{c}{ Time } & Baseline & Washout & TDCF & Latanoprost \\
\hline 8 AM & $26.5(1.78)$ & $26.4(1.62)$ & $17.2(1.40)$ & $18.7(1.07)$ \\
10 AM & $26.4(1.87)$ & $26.8(1.95)$ & $16.7(1.70)$ & $17.2(1.62)$ \\
Noon & $25.4(1.88)$ & $25.1(1.80)$ & $15.5(1.31)$ & $17.4(1.25)$ \\
2 PM & $22.3(2.78)$ & $21.7(1.70)$ & $14.7(2.06)$ & $15.4(1.65)$ \\
4 PM & $21.2(2.85)$ & $21.6(1.62)$ & $14.8(1.40)$ & $16.7(1.51)$ \\
6 PM & $21.4(2.59)$ & $21.3(2.05)$ & $15.0(2.18)$ & $16.1(1.50)$ \\
8 PM & $20.4(2.53)$ & $20.3(1.94)$ & $14.4(1.39)$ & $16.0(1.65)$ \\
10 PM & $20.7(2.03)$ & $20.1(1.29)$ & $13.4(1.40)$ & $15.0(1.87)$ \\
Midnight* & $20.0(2.42)$ & $19.9(1.68)$ & $14.4(1.95)$ & $16.6(1.72)$ \\
2 AM* & $21.2(2.22)$ & $21.2(1.32)$ & $15.8(1.51)$ & $17.0(1.74)$ \\
4 AM* & $23.7(2.20)$ & $23.8(1.60)$ & $16.4(1.11)$ & $17.4(1.53)$ \\
6 AM* & $25.1(1.82)$ & $24.5(1.76)$ & $16.7(1.14)$ & $17.0(1.02)$ \\
24-hour IOP & $22.9(3.22)$ & $22.7(2.90)$ & $15.4(1.91)$ & $16.7(1.72)$ \\
\hline & & & &
\end{tabular}

Data are expressed as the mean (SD).

* Data were obtained in participants in the supine/recumbent body position.

Latanoprost had no significant effect $(-0.01 \mathrm{~mm} \mathrm{Hg}$ [95\% CI: -0.2 to $0.11 ; P=0.463$ ), whereas the effect of TDFC was statistically significant $(-3.1 \mathrm{~mm} \mathrm{Hg}[95 \% \mathrm{CI}:-3.3$ to -2.8$]$; $P<0.0001$ ); the between-treatment difference was also statistically significant $(-3.0 \mathrm{~mm} \mathrm{Hg}$ [95\% CI: -3.3 to -2.8 ] $P<$ 0.0001 ; Fig. 1). Analysis of variance of the differences in comparison with baseline showed no treatment sequence effect $(P=0.208)$.

The reduction from baseline during the day was greater with TDFC than with latanoprost $(-3.2 \mathrm{~mm} \mathrm{Hg}$ [95\% CI: -3.5 to -2.8 ] vs. $-0.1 \mathrm{~mm} \mathrm{Hg}$ [95\% CI: -0.3 to 0.2$]$ ), and the difference between treatments was statistically significant $(-3.1 \mathrm{~mm} \mathrm{Hg}$ [95\% CI: -3.4 to -2.8 ]; $P<0.0001)$. The reduction from baseline during the night was also greater with TDFC ( $-2.9 \mathrm{~mm} \mathrm{Hg}[95 \% \mathrm{CI}:-3.3$ to -2.5$]$ vs. $-0.1 \mathrm{~mm} \mathrm{Hg}$ [95\% CI: -0.4 to 0.3 ]), and the between-treatment difference was also statistically significant $(-2.8 \mathrm{~mm} \mathrm{Hg}$ [95\% CI: -3.2 to $-2.4] ; P<0.0001)$.

\section{Diastolic Blood Pressure}

Mean 24-hour DBP was 73.5 (5.2) $\mathrm{mm} \mathrm{Hg}$ at baseline, 73.3 (5.2) $\mathrm{mm} \mathrm{Hg}$ at the end of the washout period, $71.6(5.2) \mathrm{mm} \mathrm{Hg}$ after TDFC, and $73.6(5.0) \mathrm{mm} \mathrm{Hg}$ after latanoprost. Latanoprost had no significant effect $(-0.3 \mathrm{~mm} \mathrm{Hg}[95 \% \mathrm{CI}:-0.0$ to 0.6 ]; $P=0.414)$, but that of TDFC was statistically significant

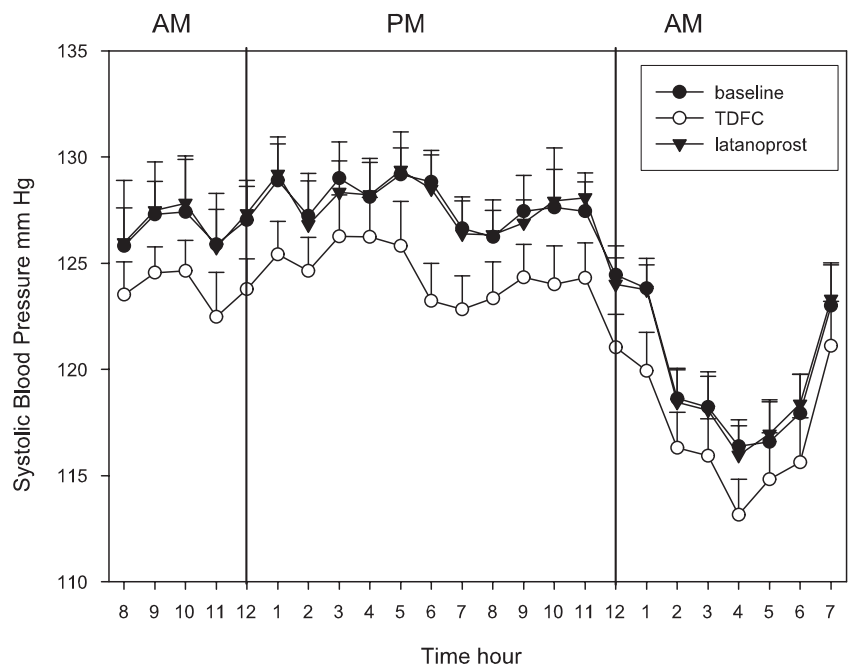

FIGURE 1. Dynamic SBP by study phase.

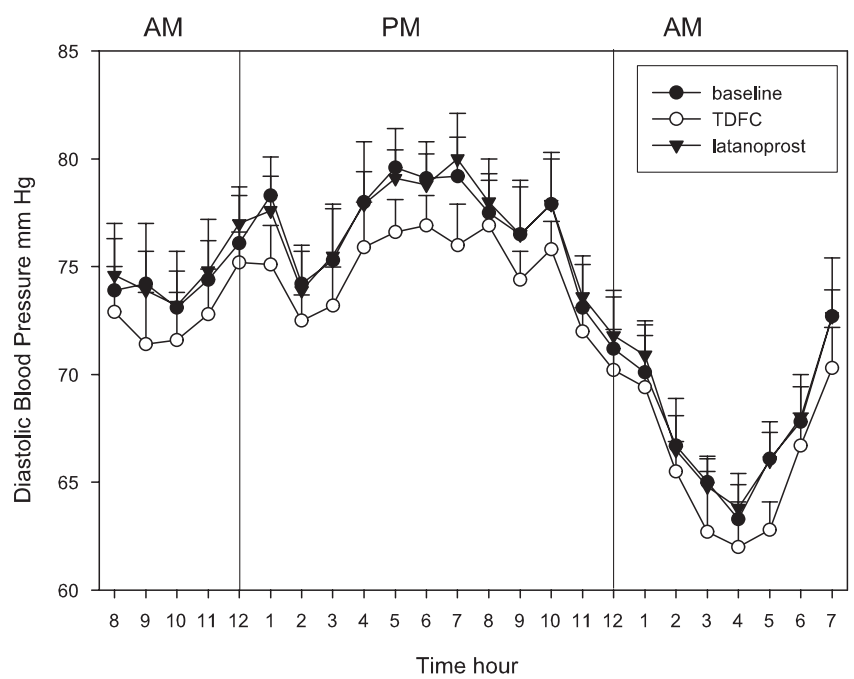

Figure 2. Dynamic DBP by study phase.

$(-1.9 \mathrm{~mm} \mathrm{Hg}$ [95\% CI: -2.2 to -1.6$] ; P<0.0001)$, and the difference between treatments was statistically significant $(-2.0 \mathrm{~mm} \mathrm{Hg}$ [95\% CI: -2.2 to -1.8 ]; $P<0.0001$; Fig. 2$)$. Analysis of variance of the differences in comparison with baseline showed no treatment sequence effect $(P=0.928)$.

The reduction from baseline during the day was greater with TDFC than with latanoprost $(-2.2 \mathrm{~mm} \mathrm{Hg}$ [95\% CI: -2.5 to -2.8 ] vs. $0.3 \mathrm{~mm} \mathrm{Hg}$ [95\% CI: -0.1 to 0.6$]$ ), and the difference was statistically significant $(-2.4 \mathrm{~mm} \mathrm{Hg}[95 \% \mathrm{CI}$ : -2.8 to -2.1 ]; $P<0.0001)$. The reduction from baseline during the night was also greater with TDFC $(-1.4 \mathrm{~mm} \mathrm{Hg}$ [ $95 \% \mathrm{CI}:-1.8$ to -0.9 ] vs. $0.4 \mathrm{~mm} \mathrm{Hg}$ [ $95 \% \mathrm{CI}: 0.0$ to 0.8 ), and the difference was statistically significant $(-1.8 \mathrm{~mm} \mathrm{Hg}[95 \%$ CI: -2.4 to -1.1 ]; $P<0.0001)$.

\section{Diastolic Ocular Perfusion Pressure}

Mean 24-hour DOPP was 50.4 (6.7) $\mathrm{mm} \mathrm{Hg}$ at baseline, 50.3 (6.5) $\mathrm{mm} \mathrm{Hg}$ at the end of the washout period, 56.4 (5.9) $\mathrm{mm}$ $\mathrm{Hg}$ after TDFC, and $56.7(5.7) \mathrm{mm} \mathrm{Hg}$ after latanoprost (Table $3)$. Both therapies significantly increased DOPP in comparison with baseline $(P<0.0001)$.

The increase from baseline was $5.9 \mathrm{~mm} \mathrm{Hg}$ (95\% CI: 5.3 to 6.5) with TDFC, and $6.5 \mathrm{~mm} \mathrm{Hg}$ (95\% CI: 5.8 to 7.1) with latanoprost, a difference that was not statistically significant

Table 3. Diastolic Ocular Perfusion Pressure by Study Phases

\begin{tabular}{lcccc}
\hline \multicolumn{1}{c}{ Time } & Baseline & Washout & TDCF & Latanoprost \\
\hline 8 AM & $47.4(3.32)$ & $47.4(2.96)$ & $55.6(2.32)$ & $55.9(2.48)$ \\
10 AM & $46.7(3.98)$ & $46.3(3.10)$ & $54.9(3.16)$ & $56.0(2.47)$ \\
Noon & $50.8(3.24)$ & $51.0(3.92)$ & $59.7(2.09)$ & $59.5(2.01)$ \\
2 PM & $52.0(4.24)$ & $53.2(3.04)$ & $57.8(3.53)$ & $58.4(2.36)$ \\
4 PM & $56.8(4.06)$ & $55.9(2.71)$ & $61.1(2.10)$ & $61.2(2.46)$ \\
6 PM & $57.7(3.76)$ & $57.3(2.46)$ & $61.9(2.95)$ & $62.7(2.49)$ \\
8 PM & $57.1(3.53)$ & $57.5(2.82)$ & $62.5(2.03)$ & $62.0(1.70)$ \\
10 PM & $57.2(2.76)$ & $57.2(2.78)$ & $62.4(2.36)$ & $62.8(2.80)$ \\
Midnight* & $51.2(3.82)$ & $50.6(2.66)$ & $55.8(2.39)$ & $55.2(2.71)$ \\
2 AM* & $45.5(3.46)$ & $44.9(2.52)$ & $49.7(2.18)$ & $49.4(2.31)$ \\
4 AM* & $39.6(2.76)$ & $39.0(2.27)$ & $45.6(2.22)$ & $46.4(2.19)$ \\
6 AM* & $42.8(2.59)$ & $43.6(2.65)$ & $50.0(1.83)$ & $50.9(2.11)$ \\
24-hour DOPP & $50.4(6.78)$ & $50.3(6.53)$ & $56.4(5.95)$ & $56.7(5.74)$
\end{tabular}

Data are expressed as the mean (SD). DOPP diastolic ocular perfusion pressure.

* Data were obtained in supine/recumbent body position; refer to the text for appropriate interpretation. 
( 0.5 [95\% CI: -0.1 to 1.2$] ; P=0.09)$. Analysis of variance showed no effect of treatment sequence $(P=0.331)$.

The increase from baseline during the day was greater with latanoprost than with TDFC (6.8 $\mathrm{mm} \mathrm{Hg}$ [95\% CI: 6.0 to 7.6] vs. $6.0 \mathrm{~mm} \mathrm{Hg}$ [95\% CI: 5.3 to 6.8]), and the difference between treatments was statistically significant $(-0.8 \mathrm{~mm} \mathrm{Hg}[95 \% \mathrm{CI}$ : -1.6 to 0.0$] ; P=0.049)$. The increase from baseline during the night was similar with TDFC and latanoprost $(5.7 \mathrm{~mm} \mathrm{Hg}$ [95\% CI: 5.0 to 6.4 ] vs. $5.7 \mathrm{~mm} \mathrm{Hg}$ [95\% CI: 5.0 to 6.5]), and the between-treatment difference was not statistically significant $(-0.02 \mathrm{~mm} \mathrm{Hg}$ [95\% CI: -1.0 to 1.0$] ; P=0.970)$.

\section{Discussion}

In comparison with no treatment, both TDFC and latanoprost significantly reduced 24-hour IOP in this group of newly diagnosed and previously untreated patients with POAG who did not have or who were being treated for systemic hypertension. TDFC reduced IOP to a significantly greater extent than did latanoprost and, unlike latanoprost, significantly reduced 24hour BP in comparison with baseline. DOPP was significantly increased by both treatments at all time points, with no significant difference between them.

TDFC reduced IOP to a significantly greater extent than latanoprost in comparison with the findings of other 24-hour investigations: Konstas et al. ${ }^{17}$ found a $0.6 \mathrm{~mm} \mathrm{Hg}$ advantage for TDFC, Orzalesi et al. ${ }^{18}$ found a $0.2-\mathrm{mm} \mathrm{Hg}$ advantage for latanoprost, and we found a $1.3-\mathrm{mm} \mathrm{Hg}$ advantage for TDFC. It should be noted that the study of Orzalesi et al. ${ }^{18}$ may have been affected by a selection bias, in that 13 of the 20 patients had systemic hypertension treated with systemic $\beta$-blockers ( 6 patients) or other unspecified medications ( 7 patients), which may have decreased the ocular hypotensive efficacy of timolol. ${ }^{20}$ All the patients in our study had POAG but no cardiovascular diseases (e.g., hypertension, cardiac insufficiency, arrhythmia), and none of them was taking any systemic medication that could modify $\mathrm{BP}$ or interfere with the hypotensive effects of timolol.

The difference between our findings and those of Konstas et al. ${ }^{17}$ may be partially attributable to the fact that our newly diagnosed and untreated patients may have been more responsive to timolol than were patients previously treated with $\beta$-blockers ${ }^{23}\left(11 / 33\right.$ patients in Konstas et al. $\left.{ }^{17}\right)$.

Latanoprost induced a uniform IOP reduction for 24 hours, but its hypotensive effect was greater during the day and 12 hours after administration, as found in previous studies. ${ }^{23-29}$ The statistically significant difference in the effects of TDFC and latanoprost observed in our study was not found in several previous studies of much larger patient samples. ${ }^{30-35}$ However, all these were based on single office or only daytime IOP measurements and did not have high $\mathrm{BP}$ and its treatment as exclusion criteria. Moreover, they all included previously treated patients or patients in whom $\beta$-blockers had failed to provide clinically acceptable control of IOP. Taken together, all these factors may have contributed to the different findings of these studies.

In line with the findings of previous studies, ${ }^{12}$ we found that latanoprost did not have any effect on 24-hour SBP or DBP, whereas TDFC reduced both, thus confirming the results of previous investigations showing that topically applied $\beta$-blockers reduce systemic BP. ${ }^{12,16,36-40}$

Given their effects on BP and IOP, both TDFC and latanoprost significantly increased DOPP at all time points, without any significant between-treatment difference in mean 24-hour DOPP values. Despite the significant reduction in BP, possibly due to the effect of timolol on $\mathrm{BP},{ }^{12,36-40}$ TDFC induced a significant increase in DOPP at all time points because of the concomitant significant reduction in IOP, which may be explained by the relevant effect of dorzolamide on IOP at night. ${ }^{12,24,41-43}$

Several limitations should be taken into account when interpreting the findings of this study. First of all, the sample size was small, although the study's crossover design had sufficient statistical power to assess any differences between the two regimens. Nevertheless, the comparison concerning DOPP may have been underpowered. Second, the population was highly selective because systemic hypertension is very frequent in the age group of patients with POAG, and our results cannot be generalized to the overall POAG population. However, systemic hypertension and its treatment were considered exclusion criteria because of their potential effect on BP due to the greater variability in $\mathrm{BP}$ in patients treated with systemic antihypertensive medications, ${ }^{19}$ and the possibly negative impact of antihypertensive medications (such as systemic $\beta$-blockers) on the hypotensive effect of timolol. ${ }^{20}$ Third, the study was only observer masked and should have been performed in a double-masked fashion to minimize any potential bias. However, this was an investigator-initiated trial, and appropriate double masking was not feasible. Fourth, perfusion pressure has been calculated by subtracting the IOP from the BP. This formula is not fully compatible with the widely used formula for the calculation of OPP [mean BP * (2/3) - IOP], which better considers the physiological pressure difference between the brachial BP and the BP close to the eyeball. Nevertheless, the DOPP, as calculated in the present study, has been found to be associated with glaucoma in several epidemiologic investigations ${ }^{6-10}$ and is probably a reasonable surrogate for the OPP when the patient is awake and in a vertical body position. Although It is well known that the relationship between OPP and systemic BP in a recumbent body position (nighttime) is different from that in a vertical body position (daytime),${ }^{44}$ it is difficult to discuss any physiological implication that could be related to the different impact of OPP during day- and nighttime. Finally, the use of a handheld tonometer (TonoPen; Bio-Rad) rather than GAT for measurement of nocturnal IOP may be a concern, as there is no close agreement between the two procedures. ${ }^{45}$ However, it did allow us to make the nighttime IOP and BP measurements with the patients in bed and supine (which may better reflect real-life conditions), thus minimally disturbing the patients and avoiding the physiological changes in BP and IOP that occur when they rise from a supine to a standing position. ${ }^{46}$ Furthermore, the fair agreement between GAT and tonometer IOP measurements should not be considered a major problem as the study design allowed the comparison of paired measurements always made at the same time: This may require a certain caution in interpreting the accuracy of the nocturnal IOP measurements, but should not have any impact on comparisons of the nighttime measurements in individual patients.

It remains to be demonstrated whether DOPP may be considered an accurate marker in the management of POAG but, as the bulk of epidemiologic and clinical evidence strongly supports considering daytime BP and DOPP as relevant elements in the multifactorial pathogenesis of POAG ${ }^{6-10}$ and possibly its progression, ${ }^{11}$ it may be clinically important to assess them in patients with treated POAG. We found that both TDFC and latanoprost increased mean 24-hour DOPP, and DOPP at all time points from $8 \mathrm{AM}$ to $8 \mathrm{PM}$, to $>50 \mathrm{~mm} \mathrm{Hg}$ (above the daytime threshold that has been shown to represent a risk for the development of $\mathrm{POAG}^{6-8,10}$ ), the former by counteracting the expected decrease in DBP with a considerable reduction in IOP, and the latter by not affecting DBP and significantly reducing IOP.

However, given the short follow-up time in this study and the relatively small sample size, our results should be inter- 
preted cautiously. Further investigations are needed to establish the long-term effects of these treatments on BP and DOPP profiles.

\section{References}

1. Kass MA, Heuer DK, Higginbotham EJ, et al. The Ocular Hypertension Treatment Study: a randomized trial determines that topical ocular hypotensive medication delays or prevents the onset of primary open-angle glaucoma. Arch Ophthalmol. 2002;120:701713; discussion 829-830.

2. Miglior S, Torri V, Zeyen N, et al.; The European Glaucoma Prevention Study Group. Intercurrent factors associated with the development of open-angle glaucoma in The European Glaucoma Prevention Study. Am J Ophthalmol. 2007;144:266-275.

3. The AGIS Investigators. The Advanced Glaucoma Intervention Study (AGIS): 7. the relationship between control of intraocular pressure and visual field deterioration. Am J Ophthalmol. 2000; 130:429- 440.

4. Heijl A, Leske MC, Bengtsson B, Hyman L, Bengtsson B, Hussein M. Reduction of intraocular pressure and glaucoma progression: results from the Early Manifest Glaucoma Trial. Arch Ophthalmol. 2002;120:1268-1279.

5. Weinreb RN, Khaw PT. Primary open-angle glaucoma. Lancet. 2004:363:1711-1720.

6. Tielsch JM, Katz J, Sommer A, Quigley HA, Javitt JC. Hypertension, perfusion pressure, and primary open-angle glaucoma: a population-based assessment. Arch Ophthalmol. 1995;113:216-221.

7. Leske MC, Connell MS, Wu SY, Hyman LG, Schachat AP. Risk factors for open-angle glaucoma. The Barbados Eye Study. Arch Ophthalmol. 1995;113:918-924.

8. Bonomi L, Marchini G, Marraffa M, Bernardi P, Morbio R, Varotto A. Vascular risk factors for primary open angle glaucoma: The Egna-Neumarkt Study. Ophthalmology. 2000;107:1287-1293.

9. Quigley HA, West SK, Rodriguez J, Munoz B, Klein R, Snyder R. The prevalence of glaucoma in a population-based study of Hispanic subjects. Proyecto VER. Arch Ophthalmol. 2002;120:954959.

10. Leske MC, Wu SY, Hennis A, et al.; Barbados Eye Study Group. Risk factors for incident open-angle glaucoma: The Barbados Eye Studies. Ophthalmology. 2008;115(1):85-93.

11. Leske MC, Heijl A, Hyman L, et al.; Early Manifest Glaucoma Trial Group. Predictors of long-term progression in the Early Manifest Glaucoma Trial. Ophthalmology. 2007;114:1965-1972.

12. Quaranta L, Gandolfo F, Turano R, Rovida F, Pizzolante T, Gandolfo E. Effects of topical hypotensive drugs on circadian IOP, blood pressure, and calculated diastolic ocular perfusion pressure in patients with glaucoma. Invest Ophthalmol Vis Sci. 2006;47: 2917-2923.

13. Hultzemann J, Owens S, Shedden A, Adamsons I, Vargas E. Comparison of the safety and efficacy of the fixed combination of dorzolamide/timolol and the concomitant administration of dorzolamide and timolol: a clinical equivalence study: International Clinical Equivalence Study Group. Br J Ophthalmol. 1998;82: 1249-1253.

14. Boyle JE, Ghosh K, Gieser DK, Adamsons IA. A randomized trial comparing the dorzolamide-timolol combination given twice daily to monotherapy with timolol and dorzolamide: Dorzolamide-Timolol Study Group. Ophthalmology. 1998;105:1945-1951.

15. Clineschmidt CM, Williams RD, Snyder E, Adamsons IA. A randomized trial in patients inadequately controlled on timolol alone comparing the dorzolamide-timolol fixed combination to monotherapy with timolol or dorzolamide: Dorzolamide-Timolol Combination Study Group. Ophthalmology. 1998;105:1952-1959.

16. Choudhri S, Wand M, Shields MB. A comparison of dorzolamidetimolol fixed combination versus the concomitant drugs. Am J Ophthalmol. 2000;130:832-833.

17. Konstas AGP, Panayiotis P Tersis I, Houliara D, Stewart WC Twenty-four hour diurnal curve comparison of commercially available latanoprost $0.005 \%$ versus timolol and dorzolamide fixed combination. Ophthalmology. 2003;110:1357-1360.

18. Orzalesi N, Rossetti L, Bottoli A, Fumagalli E, Fogagnolo P. The effect of latanoprost, brimonidine, and a fixed combination of timolol and dorzolamide on circadian intraocular pressure in patients with glaucoma or ocular hypertension. Arch Ophthalmol. 2003;121:453- 457.

19. Parati G, Faini A, Valentini M. Blood pressure variability: its measurement and significance in hypertension. Curr Hypertens Rep. 2006;8:199-204.

20. Lama PJ. Systemic adverse effects of beta-adrenergic blockers: an evidence-based assessment. Am J Ophthalmol. 2002;134:749760.

21. Palatini P, Frigo G, Bertolo O, Roman E, Da Corta R, Winnicki M. Validation of the A\&D TM-2430 device for ambulatory blood pressure monitoring and evaluation of performance according to subjects' characteristics. Blood Press Monit. 1998;3:255-260.

22. Cohen J. Statistical Power Analysis for the Behavioural Sciences. 2nd ed. Hillside, NJ: Lawrence Erlbaum, 1988.

23. Gieser SC, Juzych M, Robin AL, Schwartz GF. Clinical pharmacology of adrenergic drugs. In: Ritch R, Shields BM, Krupin T, eds. The Glaucomas. 2nd ed. St. Louis: Mosby; 1996:1425-1448.

24. Orzalesi N, Rossetti L, Invernizzi T, Bottoli A, Autelitano A. Effect of timolol, latanoprost, and dorzolamide on circadian IOP in glaucoma or ocular hypertension. Invest Ophthalmol Vis Sci. 2000;41: $2566-2573$.

25. Ràcz P, Ruzsonyi MR, Nagy ZT, Gagyi Z, Bito LZ. Around-the-clock intraocular pressure reduction with once-daily application of latanoprost by itself or in combination with timolol. Arch Ophthalmol. 1996;114:268-273.

26. Mishima HK, Kiuchi Y, Takamatsu M, Ràcz P, Bito LZ. Circadian intraocular pressure management with latanoprost: diurnal and nocturnal intraocular pressure reduction and increased uveoscleral flow. Surv Ophthalmol. 1997;41(suppl 2):S139-S144.

27. Larsson LI. Intraocular pressure over 24 hours after repeated administration of latanoprost $0.005 \%$ or timolol gel-forming solution $0.5 \%$ in patients with ocular hypertension. Ophthalmology. 2001; 108:1439-1444

28. Larsson LI, Mishima HK, Takamatsu M, Orzalesi N, Rossetti L. The effect of latanoprost on circadian intraocular pressure. Surv $\mathrm{Oph}$ thalmol. 2002;47(suppl 1):S90-S96.

29. Liu JHK, Kripke DF, Weinreb RN. Comparison of the nocturnal effects of once-daily timolol and latanoprost on intraocular pressure. Am J Ophthalmol. 2004;138:389-395.

30. Fechtner RD, McCarroll KA, Lines CR, Adamsons IA. Efficacy of the dorzolamide/timolol fixed combination versus latanoprost in the treatment of ocular hypertension or glaucoma: combined analysis of pooled data from two large randomized observer and patientmasked studies. J Ocul Pharmacol Ther. 2005;21:242-249.

31. Januleviciene I, Harris A, Kagemann L, Siesky B, McCranor L. Comparison of the effects of dorzolamide/timolol fixed combination versus latanoprost on intraocular pressure and pulsatile ocular blood flow in primary open-angle glaucoma patients. Acta Ophthalmol Scand. 2004;82:730-737.

32. Susanna R Jr, Sheu WP; Latin American Glaucoma Society. Comparison of latanoprost with fixed-combination dorzolamide and timolol in adult patients with elevated intraocular pressure: an eight-week, randomized, open-label, parallel-group, multicenter study in Latin America. Clin Ther. 2004;26:755-768.

33. Fechtner RD, Airaksinen PJ, Getson AJ, Lines CR, Adamsons IA COSOPT versus XALATAN Study Groups. Efficacy and tolerability of the dorzolamide $2 \% /$ timolol $0.5 \%$ combination (COSOPT) versus $0.005 \%$ (XALATAN) in the treatment of ocular hypertension or glaucoma: results from two randomized clinical trials. Acta Ophthalmol Scand. 2004;82:42-48.

34. Konstas AG, Kozobolis VP, Tersis I, Leech J, Stewart WC. The efficacy and safety of the timolol/dorzolamide fixed combination vs latanoprost in exfoliation glaucoma. Eye. 2003;17:41-46.

35. Honrubia FM, Larsson LI, Spiegel D; European latanoprost study group. A comparison of the effects on intraocular pressure of latanoprost $0.005 \%$ and the fixed combination of dorzolamide $2 \%$ and timolol $0.5 \%$ in patients with open-angle glaucoma. Acta Ophthalmol Scand. 2002;80:635-641.

36. Stewart WC, Stewart JA, Jackson AL. Cardiovascular effects of timolol maleate, brimonidine or brimonidine/timolol maleate in concomitant therapy. Acta Ophthalmol Scand. 2002;80:277-281. 
37. Alvan G, Calissendorff B, Seideman P, Widmark K, Widmark G. Absorption of ocular timolol. Clin Pharmacokinet. 1980;5:95100.

38. Floras JS. Antihypertensive treatment, myocardial infarction, and nocturnal myocardial ischaemia. Lancet. 1988;2:994-996.

39. Nelson WL, Fraunfelder FT, Sills JM, Arrowsmith JB, Kuritsky JN. Adverse respiratory and cardiovascular events attributed to timolol ophthalmic solution. 1978-1985. Am J Opbthalmol. 1986;102: 606-611.

40. Hayreh SS, Podhajsky P, Zimmerman MB. Beta-blocker eyedrops and nocturnal arterial hypotension. Am J Opbthalmol. 1999;128: 301-309.

41. Topper JE, Brubaker RF. Effects of timolol, epinephrine, and acetazolamide on aqueous flow during sleep. Invest Ophthalmol Vis Sci. $1985 ; 26: 1315-1319$.

42. Konstas AG, Maltezos A, Bufidis T, Hudgins AG, Stewart WC. Twenty-four hour control of intraocular pressure with dorzol- amide and timolol maleate in exfoliation and primary open-angle glaucoma. Eye. 2000;14:73-77.

43. Vanlandingham BD, Maus TL, Brubaker RF. The effect of dorzolamide on aqueous humor dynamics in normal human subjects during sleep. Opbthalmology. 1998;105:1537-1540.

44. Bill A. Physiological aspects of the circulation in the optic nerve. In: Heilmann K, Richardson KT, eds. Glaucoma: Conceptions of a Disease-Pathogenesis, Diagnosis, Therapy. Philadelphia: Saunders; 1978:97-103.

45. Tonnu PA, Ho T, Sharma K, White E, Bunce C, Garway-Heath D. A comparison of four methods of tonometry: method agreement and interobserver variability. Br J Ophthalmol. 2005;89:847-850.

46. Medeiros FA, Brandt $\mathrm{J}$, Liu JH, et al. IOP as a risk factor for glaucoma development and progression. In: Weinreb $\mathrm{RN}$, Brandt JD, Garway-Heath D, Medeiros FA, eds. Intraocular Pressure. The Hague, The Netherlands: Kugler Publications; 2007:59-74. 